\title{
Gay and Straight Possible Selves: Goals, Identity, Subjective Well-Being, and Personality Development
}

\author{
Laura A. King \\ University of Missouri \\ Nathan Grant Smith \\ Yale University
}

\begin{abstract}
This study examined the relations of the salience and elaboration of gay and straight possible selves to subjective well-being (SWB) and ego development (ED) in a sample of 107 gay men and lesbians, who wrote narrative descriptions of their straight and gay best possible selves and rated the salience of these narratives (i.e., the clarity of the mental image, how easy it was to imagine). Independent raters coded the narratives for amount of elaboration (i.e., vivid detail). The salience of the gay possible self was positively related to SWB and outness, while the salience of the straight possible self was negatively related to SWB and being out. Furthermore, the possible self variables mediated the relationship of outness to well-being. Straight self-elaboration predicted
\end{abstract}

This research was supported by NIMH Grant MH54142. Portions of this study appeared in an undergraduate honors thesis by Nathan Smith under the direction of Laura King. We thank Camille Patterson, Sonia Sethi, Jeff White, Tom Kennedy, Erik Day, Summer Noelle Smith, and Kelly Ruff for their assistance in transcription, content analysis, and coding. We thank Angie Simon for her assistance in data collection for the pilot study of 15 lesbians who provided invaluable feedback on earlier versions of the questionnaire packet. Finally, we express our gratitude to the participants in this study, who completed these questionnaire packets in the sometimes hostile contexts of their lives. We thank them for their amazing candor in sharing their life dreams in the service of this study. Correspondence concerning this article should be addressed to Laura A. King, Department of Psychological Sciences, University of Missouri, Columbia, 211 McAlester Hall, Columbia, MO 65203. Electronic mail may be sent to Laura A. King at kingla@missouri.edu

Journal of Personality 72:5, October 2004.

Blackwell Publishing 2004 
personality development concurrently and prospectively, over 2 years. Results are interpreted as indicating that, while happiness may require us to focus upon our current life goals, personality development might require an exploration of the potential sacrifices of identity.

I'm a 25 year-old male ... living in a conservative . . city. I grew up in a strict Presbyterian family in which homosexuality, if it was ever thought of, would have been considered a sin. I can't imagine that my family, any of my parents' friends, my friends or coworkers would be accepting of it. Here's the thing: since my teens, I have been attracted to men.... I am now engaged to marry a very nice woman for whom I feel some passion, but maybe not what a typical "straight" male would feel... . Would it be so wrong to her or to me to marry and have a family? I'm not a trailblazer. . . . suppose I passed this opportunity up and then discovered I really didn't like being gay? Can anyone offer advice? (Message posted to an anonymous gay Internet message board)

To some degree, all of us face the central dilemmas of emerging identity: sorting out our own values from those we have inherited from our parents, negotiating a life path within the frameworks of the families, communities, society, and culture in which we live. Identity development requires that an individual negotiate the difficult balance that must be struck between the imperative of being true to oneself and the desire to belong. Answering the question "Who am I?" can be particularly difficult for individuals who recognize that they are not necessarily growing up to be the person they had initially imagined. As the quote above illustrates, when identity development includes the realization that one is gay, issues common to all developing individuals are brought very much to the fore. In the present study, we examined the ways that thinking about and elaborating upon one's possible identities related to subject well-being (SWB) and personality development.

We asked gay men and lesbians to write narrative descriptions of their best possible future gay and straight selves. Possible selves are personalized representations of goals (Markus \& Nurius, 1986). Previous research has shown that possible selves influence memory (Kato \& Markus, 1994) and relate to superior performance (Ruvolo \& Markus, 1992), supporting the notion that these selves are motivational units, comparable to other goal units (Markus \& Ruvolo, 1989). Possible 
selves have been portrayed as psychological resources that motivate the self throughout adult development (Cross \& Markus, 1991). Possible selves make explicit the fictional future that is implicated in our goalsconcretizing the relationship between identity and motivation. Possible selves, as mental images of the person in the future, demonstrate that goal processes unfold within and, in turn, help define identity.

We examined gay and straight best possible future selves using narrative methodology. Narrated possible selves have been shown to be a rich source of information, particularly compared to selves measured via questionnaires, and to be a particularly good source for ideal selves (Whitty, 2002). Using narratives allowed us to look at two aspects of these possible selves: their salience and their elaboration. A salient possible self is one that is readily available in a person's mental life. It is likely to be thought about a great deal. Salience can be thought of as the mental investment the person makes in a particular possible self - the degree to which the person has actively considered that possible self. The elaboration of a narrative possible self, in contrast, refers to the level of vividness or rich detail included in the narrated possible self. Although these two aspects of possible selves may be related, they need not be. A very elaborate possible self may be chronically available in a person's mental life (i.e., salient) but it is also possible for someone to develop an elaborate description of a possible self that he or she has never actually entertained previously. An elaborate self may be constructed "on line" in response to a prompt to do so. In contrast, a person may have a very simple possible self that remains quite salient in his or her life. While salience refers to the current, chronic interest in a self, elaboration refers to the level of detail of a particular construction that may or may not be generated at the moment. These distinctions between salience and elaboration are important as they guide our separate hypotheses for well-being and development.

\section{Gay and Straight Possible Selves: Implications for SWB}

Goals are a crucial aspect of positive human functioning (e.g., Brunstein, 1993). Writing about one's best possible self in the future has been shown to enhance psychological and physical well-being (King, 2001a). With regard to the possible selves of gay individuals, goals that emerge out of one's gay identity ought to be important contributors to well-being. Accepting oneself as gay is an 
important aspect of psychological well-being for gay men and lesbians (Leserman, DiSantostefano, Perkins, \& Evans, 1994; Miranda \& Storms, 1989). Positivity of gay identity, rejection of negative gay stereotypes, and gay activism correlate with SWB (Luhtanen, 1996). The degree to which gay individuals invest in goals that are rooted in gay identity ought to be related to the experience of positive wellbeing. Thus, we predicted that the salience of the gay best possible self would relate to heightened SWB among gay men and lesbians.

An advantage of examining possible selves in a gay sample is the availability of an alternative self that many of these participants have at one time likely considered - their best possible straight selves. The straight best possible selves of gay people can be understood in at least two ways: They may represent either reminiscences of past goals or constructions of a possible future, at least portions of which are not readily attainable. It is plausible that at least some of our participants have negotiated a change in life goals as a result of discovering their gay identities. These individuals initially imagined themselves as straight and may have invested in a straight possible self. Certainly, this reasoning is reflected in Cass's (1979) stage model of homosexual identity development, which asserts that most individuals assume that they are probably straight (Cass, 1979; cf., Coleman, 1982). Other treatments of gay identity have stressed that gay identity may involve a departure from one's initial socialization toward a new way of living (e.g., D'Augelli, 1994). If we conceive of straight possible selves as goals that are no longer being pursued, we would expect thoughts about these goals to relate to decreased SWB. Research on parents of children with Down Syndrome (King \& Patterson, 2001) and divorced women (King \& Raspin, in press) has shown that thinking about previously cherished "lost possible selves" was associated with decreased SWB and increased distress.

Additionally, it may be that some gay people never thought of themselves as straight. However, even these individuals, at the very least, have developed a sense of identity in a context in which crucial aspects of one's sense of self stand counter to some of the essential assumptions of the dominant culture. It is safe to assume that most gay people are well aware of the conventional American Dream. Even if individuals had never considered themselves to be heterosexual, the heterosexual privileges that are withheld from them are certainly ever present and likely to be seen as advantages associated with one of life's precluded possibilities. 
Gay individuals' thoughts about their best possible straight selves may be thought of as an example of a common experience for people, in general. Anyone whose life circumstances and personal choices have placed them outside "the norm"- those in nontraditional roles, or those who have embarked on goals that differ in central ways from those that might have been expected of them, might at one time or another imagined themselves in more conventional roles. Individuals who choose a path that is in some way unusual will likely consider the benefits of "the road more traveled by," along the way. Yet, thinking about unavailable opportunities may serve as a source for envy, regret, and rumination (Lyubomirsky \& Nolen-Hoeksma, 1995; Niedenthal, Tangney, \& Gavanski, 1994; Tangney \& Salovey, 1999). Thus, again, thinking a great deal about one's best possible straight self was expected to relate to lowered levels of well-being for gay people.

\section{Gay and Straight Possible Selves: Implications for Personality Development}

In order to examine the implications of possible self-articulation for personality development, we used Loevinger's measure of ego development (ED, Loevinger \& Wessler, 1970; Hy \& Loevinger, 1996). Ego development has been referred to as development of character (Westen, 1998). At the lowest levels of ED, the person is preoccupied with issues of self-control. At higher levels of ED, the person is capable of engaging in self-regulation. The relatively immature person's internal life is characterized by basic emotions and simple wants. Maturity entails experiencing the self and world with increasing complexity. Representations of the self become richer and more differentiated. The more mature individual's mental life is marked by self-awareness, clarity, and goal-directedness. The person's relation to the social world also becomes more complex with development, moving away from conformity, fear of disapproval, and preoccupation with social norms toward a more individualized morality and a view of others characterized by a concern for identity and mutuality. Thus, ED involves the increasing capacity to self-regulate, to think complexly, and to treat others as ends rather than means (Westen 1998). Development is evidenced in the recognition of conflict and acknowledgment of the contextual nature of life choices.

This approach to personality development is well suited to this study because Loevinger's measure of maturity (The Sentence Com- 
pletion Test; SCT, Hy \& Loevinger, 1996) is unrelated to psychological adjustment (e.g., King, Scollon, Ramsey, \& Williams, 2000; Vaillant \& McCullough, 1987). Though some schemes of personality development portray positive adjustment as part of development, it is important to maintain a distinction between maturity and happiness when studying a group that might experience negative feelings due to discrimination. In addition, in examining a group of individuals who, by definition, must forego some social norms, a measure of personality development that sidesteps issues of conformity is clearly preferred (cf., Helson \& Wink, 1987).

ED has previously been shown to relate to highly complex plans and goals for the future (McAdams, Ruetzel, \& Foley, 1986). The capacity to generate clear goals and complex life plans has been suggested as a characteristic of the mature ego (Westen, 1998). Thus, we would expect that the elaboration of the gay best possible selves would relate to heightened ED. Perhaps more provocatively, there are also reasons to expect gay personality development to relate to a capacity to recognize and acknowledge a varied portrait of straight life. For individuals who had previously invested in a hoped-for straight possible self, openness to admitting the (potentially threatening) truth that, at one time, one might have imagined oneself as straight (and that those goals had value) may be a particularly good indication of maturity (cf., Stewart \& Vandewater, 1999). Supporting this idea, the elaboration of a lost possible self was associated with self-reported personal growth and ED in studies examining parents of children with Down Syndrome (King \& Patterson, 2001) and divorced women (King \& Raspin, in press).

Even for those who never imagined themselves to be straight, it seems likely that the more mature ego would express itself in the capacity to take the perspective of another and to construct a rich portrait of an alternate life path. Thus, we would expect that a gay person's ability to elaborate on his or her best possible future straight self would relate to heightened ED - demonstrating the ability of the more developed ego to take into account the value of different life experiences and identities and to view a straight life as potentially rich and meaningful.

These ideas resonate with Cass's (1979) model of gay identity development. The penultimate level of development is identity pridein which the gay person is likely to view gay life and the gay community as superior to the heterosexual alternative. In the highest stage, identity synthesis, the person is able to view the good and bad 
in both heterosexuals and homosexuals and to recognize good and supportive heterosexuals.

The elaboration of the straight possible self may be viewed as indicative not only of a person's current ED level, but of processes related to enhanced future development. The capacity to construct or reconstruct a vivid portrait of a possible future one is not pursuing resonates with processes that have been suggested as mechanisms for personality development. For instance, a common theme in many personological accounts of identity development is identity exploration (e.g., Erikson, 1968, Graafsma, 1994, Marcia, 1994). Exploration involves active questioning and self examination-trying on different selves (e.g., Marcia, 1994; Marcia, Waterman, Matteson, Archer, \& Orlofsky, 1993). The degree to which a person can generate an elaborate self that he or she is not pursuing may be a sign of previous or ongoing exploration.

In addition, if individuals had previously invested in straight possible selves, then the reconstruction of that "lost self" might be viewed as a sign of accommodation (Block, 1982) - of actively confronting the loss of one's previously cherished goals and revising one's life plan. The process of accommodation has been shown to be related to increases in ED overtime (e.g., Helson, 1992; King et al., 2000). D'Augelli $(1991,1994)$ has argued that developing a gay identity requires unusual strengths because gay men and lesbians must depart from their heterosocial socialization and seek out or define for themselves alternative ways of existing. This process might well be viewed as reflecting the process of accommodation. Loevinger (1976) referred to "pacers" as complex interpersonal situations that might pull an individual to higher levels of ED. Clearly, in the challenge of exploring one's identity and, in so doing, generating goals, confronting goal loss and generating new goals may be viewed as a pacer. Thus, the elaboration of a gay person's best possible self serves not only as a manifestation of ego level, but also, potentially, as indicative of processes related to future development. We predicted straight selfelaboration to predict personality development over time.

\section{Possible Selves and the Closet}

Anyone struggling with identity may confront the problem of announcing that identity to potentially hostile others (cf., Erikson, 1968; Marcia, 1994). Gay identity is particularly well suited to an exploration 
of articulating and publicizing identity. Degree of outness has been found to correlate positively with SWB (Luhtanen, 1996) and may be an important factor in physical health as well (e.g., Cole, Kemeny, Taylor, \& Visscher, 1996, but cf., Cole, Kemeny, \& Taylor, 1997). From a goals perspective, being out of the closet may be an indication of one's investment in identity-consistent goals and therefore is expected to be related to gay possible self-salience. Being in the closet may indicate that an individual is invested in rewards that are attached to passing as straight, and, therefore, is expected to relate to straight possible self-salience. We also examined whether the relationship of closetedness to possible self-salience and elaboration might partially explain the relationship between the closet and well-being. Possible self-characteristics were expected to mediate the relation of outness to SWB, suggesting that one reason the closet may relate to lower wellbeing is because it interferes with the enactment of important life goals.

\section{Overview and Predictions}

To summarize, gay men and lesbians wrote descriptions of their best possible future selves if they were straight and their best possible future selves as gay people. They also rated the salience of each of these possible selves and completed measures of SWB, distress, regret over gay identity, degree of outness, and ED. Two years later, a subset of the sample completed measures of SWB, distress, regret, degree of outness, and ED. Narrative possible selves were contentanalyzed for narrative richness or elaboration.

With regard to SWB, we predicted that the salience of the best possible gay self would relate to heightened SWB and lowered regret and distress. In contrast, the salience of the best possible straight self was predicted to relate to decreased SWB and heightened regret and distress.

For outness, we predicted that gay self-salience would relate to higher levels of being out and that straight self-salience would relate to lower levels of being out. Furthermore, we proposed that these possible self-characteristics would mediate the relation between outness and well-being, demonstrating that at least one of the reasons the closet is associated with distress is because it precludes the person from pursuing important life goals or indicates investment in possible selves that are essentially lacking in their ultimate promise for fulfillment. Finally, we were able to examine the potential prospective relationships between being out and well-being. Cross-sectional 
studies have shown that being out relates to well-being, but examining this relation over time allowed us to examine the possibility that happy people are more likely to come out, compared to their less satisfied counterparts.

Finally, for ED, first, we predicted that gay possible self-elaboration would relate to enhanced ED (cf., McAdams et al., 1986). Second, we predicted that straight self-elaboration would relate positively to ED. Prospectively, gay and (especially) straight possible self-elaboration were predicted to relate to ED at Time 2, controlling for Time 1 ED. This result would support the idea that the capacities revealed in possible self construction would predict increases in ED over time.

\section{METHOD}

\section{Participants and Procedures}

Advertisements in the Dallas Observer, the Dallas Met, and the Dallas Voice (a gay newspaper), and flyers posted in a gay bookstore and a women's bar in Dallas offered \$20 to gay men and lesbians for completing a mail-in survey. Participants also were recruited at an informational meeting of the Dallas Gay and Lesbian Alliance Against Defamation. Recruitment methods were specifically designed to make it clear that the study was not interested in homosexuality as a problem. Some of the print ads were headlined, "Finally, someone is going to pay you for being gay." Flyers targeted specifically towards women ("Tell us your lesbian herstory: We want to hear about your life dreams") were also used to oversample lesbians, in an attempt to attract a more gender balanced sample. Participants were told that they were being recruited because gay people would clearly represent an interesting, even expert, sample in which to examine the issues of goals and well-being.

Most participants $(60 \%)$ reported hearing about the study from the print ads. Others heard through friends $(15 \%)$, responded to the flyers $(15 \%)$, or attended the informational meeting $(10 \%)$. All recruitment methods instructed participants to call for more information. During the phone calls, the questionnaire packet was more fully described. The packet was mailed to interested participants along with a postage-paid return envelope. To ensure confidentiality, packets had blank covers, and no mention of the purpose of the study was included on the first two pages. Participants were encouraged to complete the packet at their own pace, not necessarily in one sitting.

Approximately 200 calls were received and 150 packets were distributed. $108(72 \%)$ were returned; however, in one packet, the narratives were not completed, and so this packet was not included in analyses. 
Reports from telephone calls to those who did not return the packet indicated that the reason for failure to complete the packet was the time required to do so (approximately 2 hours).

The final sample of 107 included 65 men, 39 women, and 3 not reporting. Age ranged from 18 to 66 (mean $=36.65, S D=9.68$, mode $=34$, median $=35$ ). The sample was largely White/Anglo $(87.90 \%)$, with $4.7 \%$ African American, 3.7\% Hispanic, .9\% Asian, and $2.5 \%$ other. With regard to education, a small proportion of participants had completed only grade school (3.8\%); $11.3 \%$ had completed at least high school. The modal education level was a bachelor's degree $(25.5 \%)$. A substantial proportion of participants had completed some postbaccalaureate training (a total of $25.5 \%$ for MA, JD, PhD, etc.). For $27.4 \%$, reported income was $\$ 20,000$ $\$ 40,000$. Thirty percent reported earning less than $\$ 20,000$ a year, while $38.7 \%$ reported earning more than $\$ 40,000$. Sixty-six percent were in a committed relationship. Among participants in a committed relationship, the length of relationship ranged from 10 months to 23 years $(M=3.93$ years, $S D=5.02)$. The percentage of people with whom they interacted regularly who knew they are gay ranged from 0 to $100 \%(M=71.95 \%$, $S D=27.76 ; 30 \%$ of the participants estimated themselves to be out to less than $50 \%$ of the people with whom they interact regularly). Mean age of first "gay" feelings was $12.38(S D=6.10)$ and the mean age of first homosexual relationship was $18.05(S D=13.43)$. Finally, the mean age of committing to being a gay person was $22.7(S D=7.4)$. Age of commitment to being a gay person ranged from 5 to 53 . Compared to past research on lesbians and gay men, these descriptive statistics are fairly typical. Reported ages of first homosexual sexual experience have ranged from 17 to 24 (e.g., D’Augelli, 1991, 1994; Herdt \& Boxer, 1993; Rodriguez, 1988). Age of labeling oneself as gay has been reported to range from 13 to 21 (Cohen \& Savin-Williams, 1996; Newman \& Muzzonigro, 1993; Troiden, 1979).

Upon receipt of the packet, identifying information was removed and participants were sent $\$ 20$. Two years later, participants were sent the follow-up packet. Fifty-six participants returned the follow-up packets $(53 \%)$ and were paid $\$ 20$. Attrition was due to participants leaving the area $(16 \%)$ or simply not returning the questionnaires because of the time required to do so $(33 \%)$ ). A MANOVA on all of the Time 1 measures produced no significant multivariate effect for completing the study (Wilks $F(13,80)=.82$, n.s.), and no univariate $F$ 's were significant.

Materials. Packets included instructions for completing narratives about participants' straight and gay best possible future selves. The best possible gay self instructions read as follows:

We would like you to consider the life you imagine for yourself currently, and in the future, as a gay or lesbian person. What sorts of 
things do you hope for and dream about? Imagine that your life has gone as well as it possibly could have. You have worked hard and achieved your goals. Think of this as your "best possible life" or your "happily ever after." In the space below (and on the back of this page, if necessary) write a description of the things you imagined. Be as specific as you can.

Participants then rated three items measuring the salience of the straight possible future self described in the narrative. These items included, "How easy was it for you to imagine your life in this scenario?" "How clear was the mental picture you imagined?" "How often do you think about this possible future?" Items were rated on a scale from 1 (not at all) to 6 (extremely much; $\alpha=.65$ ).

The best straight possible self was described as follows:

We would like you to consider the life you would be living if you were not a gay or lesbian person. Just about everyone has considered his or her life as it might be within the heterosexual model. We would like you to describe your "best possible" life, your "happily ever after" if you were not gay. Either try to remember how you imagined your future to be before you knew you would be living as a gay person, or imagine how your life would be if you were not gay. In the space below (and on the back of this page if necessary) describe what you think you life would be like. Be as detailed as you can. Imagine that you are heterosexual and you have worked hard and succeeded in achieving your goals. Everything in you life has gone as well as it possibly could have....what would your life be like? ${ }^{2}$

1. Talking about gay identity development as a conscious exploration process doesn't imply that being gay is a choice. Rather, our perspective is that gay individuals may well consciously consider their futures with an eye toward their own emerging desires and societal expectations. As one participant in our study noted, "The choice is not whether to be gay or not, but whether to live true to yourself or live a lie."

2. These instructions had been piloted on a subsample of 15 lesbians who assisted in refining the language so that it was not offensive to respondents. The narrative responses were examined for defensiveness. The coding was reliable $(90 \%$ agreement) and showed that $17 \%$ of the sample responded in a way that reflected some defensiveness. These responses ranged from protests that the question was heterosexist to stating that the participant was unable to "even imagine" being straight. Interestingly, nearly all of these individuals, nevertheless, did construct a narrative, as this category was unrelated to the eventual length of the straight best possible selves (point biserial $r=-.04$ ). 
Salience ratings were made using the same scale $(\alpha=.65)$. The two salience ratings were not related $(r=-.05)$ and the gay possible self was significantly more salient than the gay possible self $(M$ 's $=4.98$ vs. 2.70 , $t(105)=14.37, p<.001)$. The gay possible self narratives were somewhat longer than the straight possible self narratives $(M$ 's $=102$ and 86, paired $t(105)=3.31, p<.001)$. Individuals who committed to a gay life later in life rated their straight possible self as more salient $(r$ 's $=.24, p<.05)$. Gay best possible self-salience was related to being in a committed relationship $(r$ 's $=.28, p$ 's $<.05)$.

$S W B$ measures. The Satisfaction with Life Scale (Diener, Emmons, Larsen, \& Griffin, 1985) is a five-item measure of general life satisfaction (LS). These items are rated on a scale of 1 (strongly disagree) to 5 (strongly agree) $(M$ 's $=3.24,3.27, S D$ 's $=1.02,1.01$, for Times 1 and 2 respectively; test-retest $r=.60$ ). The Brief Symptom Inventory (Derogatis \& Spencer, 1982) measures a range of psychological symptomatology, including depression, hostility, anxiety, paranoia, phobias, and obsessive compulsive tendencies. The overall score, the Global Severity Index, was used as a measure of general distress $(M ' s=.68, .67, S D$ 's $=.48, .49$, for Times 1 and 2 respectively; test-retest $r=.49$ ).

Because thinking about unattainable goals might engender regrets, we constructed a measure of "no regrets" for this study. Participants completed six items measuring their degree of regret or second thoughts about their current gay lives. Sample items included "If I could take a pill that would make me straight I would take it," "I truly believe that the pathway to happiness for me includes being gay," "If I woke up tomorrow straight, I would truly miss aspects of my life as a gay person." These items were rated on a scale from 1 (strongly disagree) to 5 (strongly agree; $\alpha=.79$ ). ${ }^{3}$ Items were standardized prior to averaging to improve reliability (test-retest $r=.44$ ).

3. Participants also completed a standard measure of gay identity development, The Gay Identity Questionnaire (Brady \& Busse, 1994). However, this measure was problematic for a few important reasons. First, a number of participants objected to the frequent use of the term "lifestyle" in the questionnaire items. Second, the subscales for the questionnaire were not reliable when computed as described in the original article. Third, essentially, the Stage 6 subscale, which measures the highest level of gay identity development, simply functioned as a measure of SWB (and was strongly correlated with SWB measures). Likewise, the Stage 4 subscale simply served as another measure of closetedness. Because we were especially interested in examining these variables (i.e., well-being, regret, personality development, and outness) separately, this measure was not ideal for our purposes. Furthermore, because the focus of this study was on personality development, more generally, rather than gay development, specifically, we concluded that the more generic personality measures were appropriate. 
Not surprisingly, these measures were correlated. For instance, LS was related to having no regrets within time periods $(r=.37, p<.05$ at Time 1 and $r=.25, p<.10$, at Time 2). LS was also negatively related to distress within each time period and across Time periods $(r=-.48$ at Time 1, $r=-.46$ at Time 2, both $p$ 's $<.05$; and $r=-.42, p<.05$ for Time $1 \mathrm{LS}$ and Time 2 distress).

Outness. Participants rated the degree to which they were out to a variety of individuals, including, their best friend (gay or straight), their closest straight friend, other straight friends, their closest co-worker, other co-workers, mother, father, and siblings. Ratings were made on the following scale: 1 (does not know at all, to my knowledge), 2 (may have a slight awareness), 3 (definitely suspects), 4 (knows, but we've never really discussed it), 5 (knows and we've talked about it) $(\alpha=.80 ; M$ 's $=4.22$ and 4.39, $S D$ 's $=.83$ and .60 at each time period, respectively; test-retest $r=.64$ ).

$E D$. Participants completed the 18-item version of the SCT (Loevinger \& Wessler, 1970; Hy \& Loevinger 1996). Sample stems include "Women are lucky because ..." and "Education ..." When scored according to guidelines, the SCT has shown good test-retest, inter-rater, and internal consistency reliability (e.g., Loevinger \& Wessler, 1970). Longitudinal studies support the notion that the SCT measures sequential stages of personality development (e.g., Redmore \& Loevinger, 1979).

The SCT responses for both time periods were transcribed so that all responses to a given item were listed together for the entire sample and both time periods. Two raters, who had achieved at least $96 \%$ agreement with the expert scoring on practice materials and were blind to other aspects of the participants' packets, independently rated the responses in accord with the most recent scoring guidelines (Hy \& Loevinger, 1996). The absolute agreements for the 18 items ranged from $70 \%$ to $98 \%$. Counting only disparities of two levels or higher, the agreements ranged from $96 \%$ to $100 \%$, with a modal agreement level of $99.4 \%$. All disagreements were resolved by discussion. The item ratings were then regrouped according to participant and time period. Using automatic ogive rules (Hy \& Loevinger, 1996), participants were assigned total protocol scores indicating their ego levels. Although Loevinger's stages are thought to represent "types," tests for nonlinear relations were not significant. Thus, for this study, it may be best to focus on the concept of increasing ED itself, movement toward increasing capacities for self-regulation, more complex representations of self and world, increasing tolerance for ambiguity, relativism, conflict, and capacity for resolution rather than in terms of particular features of each ego level.

ED scores at Time 1 ranged from 2 to 8 , with a mode of 6 . Scores for Time 2 ranged from 3 to 9 . The modal ego level was 5. For the subsample 
completing both Time 1 and Time 2 measures, $40 \%$ stayed the same, $12 \%$ increased, and $19 \%$ dropped one level. Although ED is thought to be stable in adulthood it is not unusual to see a portion of individuals regress (Adams \& Shea, 1979, reported 21\%; White, 1985, reported 32\%). The test re-test correlation from Time 1 to Time 2 was .43, $p<.01$.

At Time 1, ED was unrelated to the SWB measures (as is typical of research comparing ED and well-being measures, e.g., King et al., 2000). However, ED at Time 2 was related to LS at Time $1(r=.29, p<.05)$. ED was positively related to education $(r ' s=.28$ and .32 at Times 1 and 2 , both $p$ 's $<.01)$. Time $2 \mathrm{ED}$ was associated with income level $(r=.36, p<.01)$. ED was correlated with coming out later in life $(r=.23$; partial $r$ controlling for age $=.23, p<.03)$. ED was unrelated to outness at either time period.

\section{Content Analyses of Straight and Gay Possible Selves}

Possible self narratives were content-analyzed for elaboration by two independent raters. Ratings were made on a 1 (not at all) to 7 (very much) scale on the following dimensions: elaboration, vividness, emotionality, and detail. Inter-rater reliabilities ranged from .73 for straight self vividness to .90 for gay self detail. ${ }^{4}$ Ratings were averaged over raters and then over the type of self described, creating two composites, gay possible self and straight possible self-elaboration $(\alpha$ for each composite $=.91)$. These two measures of elaboration were positively correlated $(r=.30, p<.01)$. The elaboration measures were unrelated to participants' salience ratings (both $r$ 's <.14). Excerpts from a highly elaborate gay possible self follow.

My partner and I will have bought our own home... . We will have at least one child. Our household is as big and noisy as I'd always dreamed. We have a lot of friends and our parents visit us often (as they do now). My partner's nieces come to visit us and know who we are and call us both "Aunt," love to come here and hang out, talking, watching soaps, and playing games. We always have animals arounddogs and cats. We live in an urban setting instead of a smaller town, but we have a great neighborhood with lots of different types of people.

4. Not surprisingly, ratings of elaboration were correlated with narrative length (for gay possible self, $r=.60$, for straight possible self, $r=.51$ ). Narrative length related to outcomes in only one case - the straight possible self narrative length was associated with ED at Time $1 r=.35, p<.01$. However, tests of the main predictions including length of narrative in the analyses did not significantly change results. For instance, the partial correlation of straight self-elaboration with ED at time 1 remained significant (partial $r=.25, p<.01$ ) controlling for length of narrative. To simplify all analyses, the ratings themselves are used throughout the results. 
She has finally really achieved her life dream of being a successful writer, and my job remains stable. We are able to take vacations to places where we truly relax. We'll grow old together, always sharing that certain magic that has kept us together and laughing for the past 8 years. We take our position as role models for younger gay people seriously and try to demonstrate every day that it is possible to have a wonderful, meaningful life as a gay person - to share our good fortune and to reach out whenever possible to make a difference in the lives of young people.

An excerpt from a gay possible self judged to be low in elaboration follows.

I hope my life is a success and I've achieved my goals, my gay lifestyle has worked well as my balanced and healthy relationship has helped me in staying focused in succeeding in my goals! I hope as well I interact with all types of lifestyles straight, gay/lesbian and am comfortable with me. I hope my family will accept my lifestyle and that God will accept my lifestyle.

Excerpts from a relatively elaborate straight possible self follow.

As I was growing up I envisioned my life to be like the lives of those I admired. Those lives were something to aspire to. I grew up in a small town... . My parents and their friends were involved in volunteer work, owned businesses, and were active in community politics. My dream was to be a veterinarian. I imagined that I was married (as that is what is supposed to happen). I dreamed that my wife would be the manager of the pet store we both owned ... we would be active in the community. Small towns can be so much fun.... I would be well known as someone who is a good person and down to earth.... The business would be successful and eventually passed down to our children.

A straight possible self judged to be low in elaboration follows.

As I am considered a handsome man, I imagine I would probably have a beautiful blonde wife to contrast to my own dark features. I probably would have concentrated more on education and not so much on partying. Therefore I'd have an executive type position, tidy house in the suburbs, and two kids.

The elaboration of the gay and straight possible selves were both positively correlated with income and education level ( $r$ 's for gay self-elab- 
oration $=.19$ and $.19, p<.05$ and for straight self-elaboration, $r$ 's $=.24$ and .30 for income and education, both $p$ 's <.005). Individuals who committed to a gay life later in life wrote more elaborate descriptions of the straight possible self. $(r=.22, p<.05)$, supporting the notion that, at least for some people, the straight possible self may represent previously considered goals. Gay possible self-elaboration was related to being in a committed relationship $(r=.39, p$ 's $<.05)$.

\section{RESULTS}

Gay and Straight Best Possible Selves, SWB, Outness, and ED

Correlations between possible self-salience and elaboration and SWB, outness, and ED are shown in Table 1. In accord with predictions, in general, salience ratings for the gay self were positively associated with well-being, while straight self-salience was negatively related to well-being. For instance, gay self-salience was positively

\section{Table 1}

Correlations of Gay and Straight Best Possible Self Salience and Elaboration, and SWB, Outness, and ED

\begin{tabular}{|c|c|c|c|c|}
\hline & \multicolumn{4}{|c|}{ Time 1} \\
\hline & \multicolumn{2}{|c|}{ Straight Self } & \multicolumn{2}{|c|}{ Gay Self } \\
\hline & Salience & Elaboration & Salience & Elaboration \\
\hline \multicolumn{5}{|l|}{ Time $1(N=107)$} \\
\hline Satisfaction With Life & $-.26 * *$ & .07 & $.30 * *$ & .02 \\
\hline Global Severity & .09 & -.05 & -.01 & $-.17 \dagger$ \\
\hline No Regrets & $-.22 *$ & .05 & $.56 * *$ & .10 \\
\hline Out & $-.29 * *$ & .07 & $.35^{* * *}$ & .11 \\
\hline Ego Development & -.11 & $.41 * *$ & .01 & .14 \\
\hline \multicolumn{5}{|l|}{ Time $2(N=56)$} \\
\hline Satisfaction With Life & -.04 & .12 & .12 & -.04 \\
\hline Global Severity & -.13 & $.20 *$ & $-.19 *$ & -.11 \\
\hline No Regrets & .05 & .02 & .02 & $-.29 *$ \\
\hline Out & -.15 & .15 & .15 & .16 \\
\hline Ego Development & -.04 & $.43 * *$ & -.19 & $.27 *$ \\
\hline
\end{tabular}

Note.

$\dagger p<.10, * p<.05, * * p<.01$, two-tailed. Time $2=$ two-year follow-up. 
associated with LS. Straight self-salience was negatively related to LS and having no regrets. In general, Time 1 possible-self measures did not correlate with Time 2 well-being measures, except that Time 1 salience ratings were related to distress at Time 2 (gay salience negatively, and straight salience positively). As predicted, gay self-salience was associated with being more out of the closet, while straight self-salience related to being more closeted, within but not across time periods. Contrary to predictions, gay self-elaboration was not consistently related to ED; it was related to ED at Time 2 but not at Time 1. However, as predicted, elaboration of the straight self was significantly correlated with ED at both time periods.

\section{Multivariate Analyses for Time 1 Measures}

Table 2 shows the results of regression equations predicting each outcome measure from the possible self variables (all from Time 1), entering the predictors simultaneously.

$S W B$. As predicted, LS was associated with the salience of the gay self (positively) and the straight self (negatively). In addition, the "no regrets" measure was negatively related to straight self-elaboration, but positively related to both the elaboration and salience of the gay

Table 2

Regression Equations Predicting SWB, Outness, and ED From Gay and Straight Possible Selves, Time 1

\begin{tabular}{lcccccc}
\hline & \multicolumn{2}{c}{ Straight Self } & & \multicolumn{2}{c}{ Gay Self } & \\
\cline { 2 - 3 } Criterion & Salience & Elaboration & & Salience & Elaboration & $\mathrm{R}^{2}$ \\
\hline Life Satisfaction & $-.26^{* *}$ & .19 & & $.28^{* *}$ & -.15 & $.14^{* * *}$ \\
No Regrets & .04 & $-.30^{*}$ & & $.43^{* *}$ & $.20^{* *}$ & $.27^{*}$ \\
Global Severity & .08 & -.01 & & .02 & -.13 & n.s. \\
Out & $-.32^{* *}$ & .07 & & $.31^{* *}$ & .07 & $.24^{* *}$ \\
Ego Development & -.13 & $.31^{* *}$ & & -.13 & .19 & $.21^{* *}$ \\
\hline
\end{tabular}

Note.

$* p<.05, * * p<.01$, two-tailed. $N=107$. Coefficients are standardized beta weights. Coefficients in the same row refer to the same equation. 
self. The result for straight self-elaboration supports the idea that exploring possible selves one is not pursuing may well engender regret over missed opportunities. Because being in a romantic relationship was associated with LS and gay self-salience, a regression equation was computed predicting LS from being in a romantic relationship and straight and gay self-salience. Even controlling for relationship status, gay self-salience contributed positively to LS and straight self-salience contributed negatively to LS $(\beta$ 's $=.29,-.25$, .24 for gay self-salience, straight self-salience and romantic relationship status, respectively, all $p$ 's $<.02$ ).

Outness. As predicted, the salience of the possible selves both contributed to the prediction of outness (straight self, negatively, and gay self-salience, positively).

$E D$. Once again, gay self-elaboration was not related to ED. However, as predicted, ED was associated with the elaboration of the straight self. Because ED and gay and straight self-elaboration were related to education and income level, regression equations were computed predicting ED at Time 1 from the elaboration variables and income and education. The only significant predictor of ED in this equation was straight self-elaboration $(\beta=.33, p<.002)$. Because straight possible self-elaboration and Time 1 ED were both associated with age of coming out, a regression equation predicting ED from age of coming out and the straight and gay possible selfelaboration was computed. Results indicated that only straight possible self-elaboration predicted ED $(\beta=.36, p<.01)$, while, controlling for straight self-elaboration, age of coming out was unrelated to $\operatorname{ED}(\beta=.10$, n.s. $)$.

\section{Outness, Possible Selves, and Well-Being: Mediational Analyses}

As in past research, degree of outness was positively related to measures of well-being within each time period ( $r$ 's $=.27, p<.05 ; .49$, $p<.01$; and $-.18, p<.10$ for LS, and No Regrets, and distress at Time 1 and $r=.28, p<.05$ for LS at Time 2). Time 1 LS was significantly related to outness at Time $2(r=.34, p<.05)$ and No Regrets at Time 1 was marginally related to outness at Time $2(r=.22)$, suggesting, perhaps, that being out may not be as much as contributor to SWB as a product of it.

Mediational analyses were conducted to examine whether the relation of outness to well-being might be mediated by the relation of 
outness to possible self-salience. For these analyses, LS, the most consistent correlate of possible self-salience and outness was used as the criterion. First, in separate analyses, outness, gay self-salience and straight self-saliance were all shown to be significant predictors of LS $(\beta$ 's $=.27, .30$, and -.25 all $p$ 's $<.05$, for outness, gay selfsalience and straight self-salience, respectively). Recall that these predictors were also related to each other (as described in the Method section), and, as shown in Table 2, possible self measures related to outness, justifying the examination of mediational model (Baron $\&$ Kenny, 1986). Regression analyses were conducted to address the potential mediation of outness-LS relationship by the relation of outness to possible selves (Baron \& Kenny, 1986). In a regression equation predicting LS, entering outness on the first step contributed significantly to the $R^{2}(.07, p<.01 ; \beta=.27)$. Entering the possible self-salience measures on the second step accounted for a significant change in $R^{2}(.10, p<.004)$, and the beta for outness was no longer significant $(\beta=.10$, n.s.), while gay self-salience $(\beta=.26)$ and straight self-salience $(\beta=-.22)$ remained significant predictors of LS. Analyses entering the possible self variables first produced the same results, though outness no longer produced a significant increment in $R^{2}$ on the second step. Thus, the effect of outness on wellbeing appears to be at least partially mediated by salience of possible selves (with the $\beta$ for outness dropping from .27 to .10). These analyses suggest that one of the reasons the closet may be detrimental to well-being is that it prevents individuals from investing in identityconsistent goals.

\section{Prospective Analyses}

Using the subset of participants who returned the two-year followup packet, prospective relationships were examined for well-being, outness, and ED.

$S W B$. First, none of the possible self variables predicted Time $2 \mathrm{LS}$ or regrets at Time 2, controlling for their Time 1 levels because, generally, the Time 1 criteria accounted for most of the variance at Time 2. However, with regard to distress, prospective relations did emerge. Time 2 distress was regressed on Time 1 distress $(\beta=.44$, $p<.001)$ in the first step $\left(R^{2}\right.$ change $\left.=.24, p<.001\right)$, and Time 1 possible self measures in the second step $\left(R^{2}\right.$ change $\left.=.17, p<.05\right)$. In this case, even controlling for Time 1 distress, the salience of the 
gay self at Time 1 contributed to the prediction of Time 2 distress $(\beta=-.37, p<.008)$. The equation predicted $40 \%$ of the variance in Time 2 distress $(F(5,38)=5.15, p<.002)$. Thus, investment in one's best possible gay self was associated with decreasing distress over time.

Outness. In an equation predicting Time 2 outness from possible self variables, controlling for Time 1 outness, no significant predictors emerged, beyond Time 1 outness. Time 2 outness was also regressed on the well-being measures and Time 1 outness to examine whether being out might be a consequence, rather than predictor, of well-being. No significant predictors were found.

$E D$. Recall that results at Time 1 supported the prediction that straight self-elaboration would be related to ED. This result may demonstrate one of the capacities of the developed ego - to elaborate on an alternative life path. The follow-up data allow us to examine whether such a capacity also relates to personality development overtime. To address this question, a hierarchical regression equation was computed, regressing Time 2 ED on Time 1 ED, on the first step, and the possible self-elaboration measures on the second step. Results are shown in Table 3. Controlling for Time 1 ED, straight self-elaboration still predicted Time 2 ED. Thus, individuals who demonstrated the capacity to elaborate on a possible self they were not pursuing showed gains in ED two years later.

It may be noted that ED and straight self-elaboration were related to a variety of other variables including education, age, age of com-

\section{Table 3}

Time 2 ED as a Function of Gay and Straight Possible Self-Elaboration, Controlling for Time $1 \mathrm{ED}$

\begin{tabular}{lccc}
\hline Variables entered on Step & Standardized $\beta$ & $t$ & Significance \\
\hline Step 1, $R^{2}$ Change $=.16^{* *}$ & & & \\
Time 1 ED & $.28^{*}$ & 2.14 & .003 \\
Step 2, $R^{2}$ Change $=.10^{*}$ & & & \\
Gay Self-elaboration & .04 & .28 & n.s. \\
Straight Self-elaboration & $.33^{*}$ & 2.44 & .02 \\
\hline
\end{tabular}

Note. For the equation, $F(3,50)=5.83, p<.002 . R^{2}=.26$.

$* p<.05, * * p<.01$. 
mitting to a gay identity, and income. In order to insure that the prospective results uncovered were not due to these other variables, another regression equation was computed. In this equation, regressing Time 2 ED on Time 1 ED, straight self-elaboration, gay selfelaboration, education, age, age of commitment to gay identity, and income, Time 1 ED predicted Time 2 ED with marginal significance $(\beta=.22, p<.10)$ and straight self-elaboration predicted Time 2 ED significantly $(\beta=.34, p<.03)$. No other variables contributed to the equation $\left(R^{2}=.30, p<.008\right)$.

\section{DISCUSSION}

This study addressed the relations of possible selves to two important aspects of adult personality: well-being and development. Results indicate that investment in hoped-for futures that are embedded in identity is associated with enhanced concurrent psychological well-being and lowered distress overtime. In contrast, preoccupation with future life dreams that are not part of that identity is associated with lowered well-being and heightened regrets and distress. In addition, the salience of one's hoped-for gay possible self was associated with the tendency to have that identity be made public, while the salience of one's straight possible self was associated with being more closeted. These results demonstrate the relation of goals to well-being and suggest that happiness is related to the pursuit of identity-consistent goals and the capacity to disengage fully from unattainable goals. Additionally, we found that while being out was associated with heightened life satisfaction, this relation was mediated by the salience of gay and straight best possible selves. In contrast to the results for well-being, ego development was more strongly related to the elaboration of the straight possible self. While thinking about goals that one cannot pursue is related to lower SWB and elaborating on such goals may relate to regret, the capacity to elaborate up on a path not taken - the best possible self one is not pursuing - is associated with personality development, concurrently and over two years, even controlling for a variety of potential confounds. These findings have implications for our understanding of not only gay and lesbian well-being and development but also for understanding these processes more generally. 
Possible Selves and Well-Being: Goals We Pursue and Those We Do Not

Finding that the salience of the gay best possible self related to concurrent SWB as well as reduced distress over time is in keeping with a long history of studies on the relations of goals to SWB (e.g., Brunstein, 1993). In this study, the salience and elaboration of these different best possible selves were pitted against each other as predictors of SWB and were found to contribute to the prediction of SWB independently. That is, even as the salience of current goals related to SWB, the salience of goals one is not pursuing was associated with distress. Results with regard to elaboration and regret are relevant here as well. The more elaborate the gay possible self was, the less regret individuals felt over their gay identities, and the more elaborate the straight possible self was, the more regret they reported experiencing. These results speak to the psychological trade-offs of the "examined life." Individuals who have thought deeply about their possible selves may incur some sense of legitimate regret over missed opportunities or positives of a road not taken. Previous research has demonstrated that preoccupation with "lost possible selves" is associated with lowered SWB and heightened regrets (King \& Patterson, 2001, King \& Raspin, in press). Though they may emerge from loss, these feelings may also occur as a result of more garden-variety identity exploration, an exploration that may require one to recognize one's life choices as only a subset of promising possibilities in life (King \& Burton, 2003).

\section{Possible Selves, Outness, and Well-Being}

The present results replicate previous research showing that being out is associated with heightened SWB and physical health (e.g., Cole et al., 1997; Luhtanen, 1996). It is important to note, however, that being out may not be wholly associated with positive outcomes. For instance, research has shown that being out may not be associated with superior functioning for those who are high on rejection sensitivity (Cole et al., 1997). For individuals high on concern over interpersonal rejection, the closet may, in fact, have a protective effect. Thus, it may be that the fit between an individual's personal style and preferences may be more important than being out, per se. In this study, we found that outness was associated with thinking less about one's best possible straight self and thinking more about one's 
best possible gay self. The relation between outness and well-being was mediated by these possible self variables. To the extent that the closet interfered with the investment in one's best possible self or increased concern for a precluded possibility, it was associated with lowered life satisfaction. These results indicate that the relationship of closetedness to well-being may be (at least partially) understood within a context of the pursuit of valued life goals. If a closeted individual is capable of investing in personally valued goals, the negative effects of the closet may be avoided, at least to some extent.

This discussion has relevance for publicizing other aspects of identity (not just sexual orientation) that may be hidden. For instance, imagine a person whose own political views diverge sharply from those of his or her family. Must these views be made known? Our results indicate that the answer is "It depends." Nearly two decades ago, Buck (1984) asserted that it is "the social support and personal consistency of a coping style that determine its protective effect" (p. 241). Adulthood requires compromises. Our results, as well as those of past research, suggest that if individuals are able to enact their goals (or behave in personally consistent ways), the extent to which their lives conform to some ideal may be irrelevant. Unfortunately, prospective analyses of outness yielded no significant results and therefore failed to illuminate the contribution of possible selves and well-being to the process of publicizing identity. Research examining these issues in a sample of younger or more recently "out to self" gay people will be necessary to predict the variables associated with coming out.

\section{Possible Self-Elaboration, Personality Development, and Regrets}

Gay self-elaboration was largely unrelated to ego development, controlling for straight self-elaboration. Although this result contrasts with past research (McAdams, Ruetzel, \& Foley, 1986), it jibes with our view of straight self-elaboration as potentially more indicative of processes that are expressions of and instrumental to personality development. Concurrently, straight self-elaboration was related to higher levels of ED. Prospectively, straight self-elaboration predicted increases in ego development over two years, even controlling for a number of potential mediators. This finding is all the more impressive given that ego development is unlikely in adulthood and that it obtained even when controlling for a number of potential mediators. 
An interesting aspect of these findings is that straight self-elaboration was also related to a heightened sense of regret over one's gay identity. This finding may indicate that some aspects of the journey toward maturity may entail the sacrifice of wholly positive feelings. Development may engender some sense of realistic regret. ${ }^{5}$

\section{Limitations}

There are a few aspects of this study that may limit the conclusions that can be drawn from our results. One potential weakness is the selection of the straight possible self as the alternate possible self for this sample. We selected the straight possible self because it was an obvious alternative self for gay people. One aspect of this choice, however, is that it also pitted the gay best possible self against a challenging and ever-present symbol of one's oppressed status. Being able to elaborate on such a possible self may be a particularly good indication of personality development. It remains ambiguous whether our results would obtain using a possible self selected by participants. Whether our results are unique to straight self-elaboration or may be generalizable to any number of alternate selves remains open to question.

Second, our sample was drawn from a geographical region that is typically considered part of the Bible Belt. The extent to which a sample of gays living in such a context is representative of gays in general is unknown. Dallas is a large metropolitan city with a large and well-established gay neighborhood, a large gay population, and numerous gay organizations and gay services. Previous research on gay samples has often relied on individuals recruited at Gay Pride events and thus has likely excluded individuals who might be closeted or not involved in such activities. The fact that our results with regard to well-being and outness replicate other research in this area indicates that our sample is not so dissimilar from those collected in other places. Regardless of whether gay people from the Dallas Metroplex are representative of gay people in general, we argue that our sample may be quite generalizable to people in general, gay or

5. It may be noted that ED was unrelated to the salience of possible selves. This lack of relation is understandable in that we asked participants about their current thoughts about the self. It may be that constructing an elaborate narrative reveals that one has thought about that self (perhaps in the past), but it is not necessary that the self be actively present in the person's mental life. 
otherwise. The important results of this study - that accessibility of goals that emerge from and are embedded within identity is a strong correlate of well-being and predicts lowered distress over time and that the exploration of an alternative life path is associated with enhanced personality development - are consistent with research and theory on well-being and development.

A potential limitation of this study is the role of verbal ability in our findings. Personality development was measured using verbal productions, as were gay and straight self-elaboration. However, if the results were simply a manifestation of verbal ability (or some other general trait), we would expect that this ability would lead to parallel findings for the gay and straight possible selves, but clearly these did not emerge.

Minority identities have been previously studied within frameworks derived from more social psychological approaches and have focused, therefore, on stigma, stigma consciousness, spoiled identity, social comparison, etc. In this study, in contrast, we were most interested in tapping into personal constructions of the future and in using gay experience as a forum for uncovering more general processes. Gay men and lesbians provide an ideal sample through which to explore such issues. Addressing whether our results generalize to other minority groups (or whether the processes we studied demonstrate differing relations in other groups) is a goal for future research.

\section{CONCLUSION}

The results of this study provide evidence of the role of cherished future selves in the processes related to two life outcomes: happiness and maturity. Pursuing goals centered in one's identity is associated with enhanced well-being, concurrently, and lowered distress over time. Furthermore, publicizing one's identity is related to the salience of identity-consistent goals. Investment in goals that are not consistent with one's identity is associated with lower well-being and hiding one's identity. Yet, the capacity to elaborate on such goals, though associated with increasing feelings of regret, is a predictor of personality development over time. The happy, mature person (King, 2001b) may be one who is able to acknowledge what is regrettable in life without being consumed by it (cf., Stewart \& Vandewater, 1999) and to see the multitude of best possible lives that may be sources of fulfillment (cf., Ryff, 1991). 


\section{REFERENCES}

Adams, G. R., \& Shea, J. (1979). The relationship between identity status, locus of control, and ego development. Journal of Youth and Adolescence, 8, 81-89.

Baron, R. M., \& Kenny, D. A. (1986). The moderator-mediator variable distinction in social psychological research: Conceptual, strategic, and statistical considerations. Journal of Personality and Social Psychology, 51, 1173-1182.

Block, J. (1982). Assimilation, accomodation, and the dynamics of personality development. Child Development, 53, 281-295.

Brady, S., \& Busse, W. J. (1994). The Gay Identity Questionnaire: A brief measure of homosexual identity formation. Journal of Homosexuality, 26, 1-22.

Brunstein, J. C. (1993). Personal goals and subjective well-being: A longitudinal study. Journal of Personality and Social Psychology, 65, 1061-1070.

Buck, R. W. (1984). The communication of emotion. New York: Guilford.

Cass, V. C. (1979). Homosexual identity formation: A theoretical approach. Journal of Homosexuality, 4, 219-235.

Cohen, K. M., \& Savin-Williams, R. C. (1996). Developmental perspectives on coming out to self and others. In R. C. Savin-Williams \& K. M. Cohen (Eds.), The lives of lesbians, gays, and bisexuals (pp. 113-151). New York: Harcourt Brace.

Cohn, L. S. (1998). Age trends in personality development: A quantitative review. In P. M. Wesatenberg, A. Blasi , \& L. D. Cohn (Eds.), Personality Development (pp. 133-144). Mahwah, NJ: Lawrence Erlbaum.

Cole, S. W., Kemeny, M. E., \& Taylor, S. E. (1997). Social identity and physical health: Accelerated HIV progression in rejection-sensitive gay men. Journal of Personality \& Social Psychology, 72, 320-335.

Cole, S. W., Kemeny, M. E., Taylor, S. E., \& Visscher, B. R. (1996). Elevated physical health risk among gay men who conceal their homosexual identity. Health Psychology, 15, 243-251.

Coleman, E. (1982). Developmental stages of the coming out process. Journal of Homosexuality, 7, 31-43.

Cross, S., \& Markus, H. (1991). Possible selves across the life span. Human Development, 34, 230-255.

D'Augelli, A. R. (1991). Teaching lesbian/gay development: From oppression to exceptionality. Journal of Homosexuality, 22, 213-227.

D’Augelli, A. R. (1994). Identity development and sexual orientation: Toward a model of lesbian, gay, and bisexual development. In E. J. Trickett \& D. Birman (Eds.), Human diversity: Perspectives on people in context (pp. 312-333). San Francisco: Jossey-Bass.

Derogatis, L. R., \& Spencer, P. M. (1982). The Brief Symptom Inventory (BSI). Baltimore: Clinical Psychometric Research.

Diener, E., Emmons, R. A., Larsen, R. J., \& Griffin, S. (1985). The satisfaction with life scale. Journal of Personality Assessment, 49, 71-75.

Erikson, E. H. (1968). Identity, youth, and crisis. New York: Norton.

Graafsma, T. L. G. (1994). A psychoanalytic perspective on the concept of identity. In H. A. Bosma, T. L. G. Graafsma, H. D. Grotevant, \& D. J. de Levita (Eds.), Identity and Development: An Interdisciplinary Approach (pp. 41-62). London: Sage. 
Helson, R. (1992). Women's difficult times and rewriting the life story. Psychology of Women Quarterly, 16, 331-347.

Helson, R., \& Wink, P. (1987). Two conceptions of maturity examined in the findings of a longitudinal study. Journal of Personality and Social Psychology, 53, 531-541.

Herdt, G., \& Boxer, A. M. (1993). Children of horizons: How gay and lesbian teens are leading a new way out of the closet. Boston: Beacon Press.

Hy, L. X., \& Loevinger, J. (1996). Measuring ego development (2nd ed.). Mahwah, NJ: Lawrence Erlbaum.

Kato, K., \& Markus, H. R. (1994). The role of possible selves in memory. Psychologia, 36, 73-83.

King, L. A. (2001a). The health benefits of writing about life goals. Personality and Social Psychology Bulletin, 27, 798-807.

King, L. A. (2001b). The hard road to the good life: The happy, mature person. The Journal of Humanistic Psychology, Special Issue on Positive Psychology, 41, 51-72.

King, L. A., \& Burton, C. M. (2003). The hazards of goal pursuit. In E. Chang \& L. Sanna (Eds). Virtue, vice and personality: The complexity of behavior (pp. 53-70). Washington, DC: APA.

King, L. A., \& Patterson, C. (2001). Reconstructing life goals after the birth of a child with Down Syndrome: Finding happiness and growing. International Journal of Rehabilitation and Health, 5, 14-21.

King, L. A., \& Raspin, C. (in press). Lost and found possible selves, well-being and ego development in divorced women. Journal of Personality.

King, L. A., Scollon, C. K., Ramsey, C. M., \& Williams, T. (2000). Stories of life transition: Happy endings, subjective well-being, and ego development in parents of children with Down Syndrome. Journal of Research in Personality, 34, 509-536.

Leserman, J., DiSantostefano, R., Perkins, D. O., \& Evans, D. L. (1994). Gay identification and psychological health in HIV-positive and HIV-negative gay men. Journal of Applied Social Psychology, 24, 2193-2208.

Loevinger, J. (1976). Ego development: Conceptions and theories. San Francisco: Jossey-Bass.

Loevinger, J. (1998). Completing a sentence. In P. M. Wesatenberg, A. Blasi, \& L. D. Cohn (Eds.), Personality development (pp. 347-354). Mahwah, NJ: Lawrence Erlbaum.

Loevinger, J., Cohn, L. D., Bonneville, L. P., Redmore, C. D., Streich, D. D., \& Sargent, M. (1985). Ego development in college. Journal of Personality and Social Psychology, 48, 947-962.

Loevinger, J., \& Wessler, R. (1970). Measuring ego development: Vol. 1. Construction and use of a sentence completion test. San Francisco: Jossey-Bass.

Luhtanen, R. (1996, August). Psychological well-being in lesbians and gay men. Presented at the American Psychological Association Convention, Toronto, Canada.

Lyubomirsky, S., \& Nolen-Hoeksma, S. (1995). Effects of self focused rumination on negative thinking and interpersonal problem solving. Journal of Personality and Social Psychology, 69, 176-190.

Marcia, J. E. (1994). The empirical study of ego identity. In H. A. Bosma, T. L. G. Graafsma, H. D. Grotevant, \& D. J. de Levita (Eds.), Identity and development: An interdisciplinary approach (pp. 67-80). London: Sage. 
Marcia, J. E., Waterman, A. S., Matteson, D. M., Archer, S. L., \& Orlofsky, J. (1993). Ego identity: A handbook for psychosocial research. New York: SpringerVerlag.

Markus, H., \& Nurius, P. (1986). Possible selves. American Psychologist, 41, 954-969.

Markus, H., \& Ruvolo, A. (1989). Possible selves: Personalized representations of goals. In L. A. Pervin (Ed.), Goal concepts in personality and social psychology (pp. 211-242). Hillsdale, NJ: Lawrence Erlbaum Associates.

McAdams, D. P., Ruetzel, K., \& Foley, J. M. (1986). Complexity and generativity at mid-life: Relations among social motives, ego development, and adults' plans for the future. Journal of Personality and Social Psychology, 50, 800-807.

Miranda, J., \& Storms, M. (1989). Psychological adjustment of lesbians and gay men. Journal of Counseling and Development, 68, 41-45.

Newman, B. S., \& Muzzonigro, P. G. (1993). The effects of traditional family values on the coming out process of gay male adolescents. Adolescence, 28, 213-226.

Niedenthal, P. M., Tangney, J. P., \& Gavanski, I. (1994). "If only I weren't" versus "If only I hadn't": Distinguishing shame and guilt in counterfactual thinking. Journal of Personality and Social Psychology, 67, 585-595.

Redmore, C., \& Loevinger, J. (1979). Ego development in adolescence: Longitudinal studies. Journal of Youth and Adolescence, 8, 1-20.

Rodriguez, R. A. (1988, August). Significant events in gay identity development: Gay men in Utah. Paper presented at the 96th Annual Convention of the American Psychological Association. Atlanta, GA.

Ruvolo, A. P., \& Markus, H. R. (1992). Possible selves and performance: the power of self-relevant imagery. Social Congition, 10, 95-124.

Ryff, C. D. (1991). Possible selves in adulthood and old age: A tale of shifting horizons. Psychology and Aging, 6, 286-295.

Stewart, A. J., \& Vandewater, E. A. (1999). "If I had it to do it over again ...": Midlife review, midcourse corrections, and women's well-being in midlife. Journal of Personality and Social Psychology, 76, 270-283.

Tangney, J. P., \& Salovey, P. (1999). Problematic social emotions: Shame, guilt, jealousy, and envy. In R. Kowalski \& M. R. Leary (Eds.), The social psychology of emotional and behavioral problems: Interfaces of social and clinical psychology (pp. 167-195). Washington, DC: APA.

Troiden, R. R. (1979). Becoming homosexual: A model of gay identity acquisition. Psychiatry, 42, 362-373.

Vaillant, G. E., \& McCullough, L. (1987). The Washington University Sentence Completion Test compares with other measures of adult ego development. American Journal of Psychiatry, 144, 1189-1194.

Westen, D. (1998). Loevinger's theory of ego development in the context of contemporary psychoanalytic theory. In P. M. Westenberg, A. Blasi, \& L. D. Cohn (Eds.), Personality Development: Theoretical, empirical and clinical investigations of Loevinger's conception of ego development (pp. 59-70). Mahwah, NJ: Erlbaum.

White, M. S. (1985). Ego development in adult women. Journal of Personality, 53, 561-574.

Whitty, M. (2002). Possible selves: And exploration of the utility of a narrative approach. Identity, 2, 211-228. 
This document is a scanned copy of a printed document. No warranty is given about the accuracy of the copy. Users should refer to the original published version of the material. 